\title{
Sustainable urban development based on energy and resource conservation concepts
}

\author{
Tatyana Pershina ${ }^{1 *}$ [0000-0002-8774-3370], Tatyana Lymareva ${ }^{10000-0002-0184-8113]}$, Andrey \\ Zhipetsky ${ }^{1}$ [0000-0002-0724-4724] \\ ${ }^{1}$ Volgograd State Technical University, 400005, Lenin avenue, Volgograd, Russia
}

\begin{abstract}
In recent years, environmental-oriented concepts of sustainable urban development have been actively developing, in particular, in the spheres of energy efficiency and resource conservation in the context of the theory of thrift, smart and environmentally-oriented creation. Four scientific concepts can be distinguished from a set of scientific theories and methodological approaches: industrial metabolism; control «on the pipe»; social and ecological metabolism, thrifty production. In particular, the concept of «lean manufacturing» has shown its effectiveness in practice in many countries in various industries. This concept is environmentally friendly, has a high potential for implementation, but is not sufficiently appreciated by domestic enterprises. Despite its widespread implementation and development, the lack of its implementation at domestic industrial enterprises is explained by the lack of adapted methods and tools for resource conservation management based on this concept. It explains the relevance of the study, which proposes a theoretical and methodological substantiation of the program for a phased transition to «lean manufacturing», which ensures an increase in the efficiency of enterprises in modern conditions, which will increase the sustainability of cities ultimately.
\end{abstract}

Keywords: sustainable development, lean manufacturing, resource saving, efficiency, metallurgical industry, enterprise.

\section{Introduction}

According to scientists, mankind will face global environmental problems and resource scarcity in 50 years [1-5]. But in the activities of almost all organizations there are huge resource losses and irrationality of their use [6]. To ensure future generations without cataclysms and environmental disasters, it is already necessary to put the tasks of resource saving and environmental responsibility as a priority. All economic activity at all stages of development is aimed at obtaining and transforming, consuming primary natural resources, in the process of creating secondary resources that provide all types and directions of human activity. Since 1998, the problem of resource saving has come to the fore in the context of global strategies for sustainable development, since the rationalization of the use of natural resources is objectively determined as a result of the destabilization of the

${ }^{*}$ Corresponding author: tatpersh@yandex.ru 
ecosystem state due to the intensive development of productive forces, active population growth and a significant load on the natural environment [7-8]. Ensuring the rational use of natural resources and the creation of effective resource-saving management systems at the enterprise are necessary to reduce the impact on the environment to an environmentally safe level.

According to the authors, the adequate model of resource saving management, based on an environmentally oriented approach, should be created for each enterprise, which predetermines the particular relevance of this study.

To achieve this goal, the authors solved the following tasks:

1. the assessment of the factors of resource conservation at the enterprise and the factors, which ensure the environmentally-oriented use of resources at the enterprise, is investigated and given;

2. the trends in the introduction of «lean manufacturing» have been analyzed and a model of the economic mechanism for managing resource conservation at the enterprise has been developed;

3. a project and a program for the phased implementation of lean manufacturing have been developed and an assessment of its feasibility has been given on the example of a separate type of work.

The subject of the research is the factors of resource saving management in modern conditions within the framework of an environmentally-oriented approach, and the object is an enterprise of the metallurgical industry (for example, JSC Volgograd Metallurgical Plant «Krasny Oktyabr»), and specifically its activities and the use of resources.

\section{Materials and methods}

To achieve the goals set in the study, the authors analyzed the approaches to the term «resource saving» [9-11].

The approaches to the interpretation of the term «resource saving»

1. Based on the interpretation of the term «resources»:

- thrifty attitude for natural resources;

- saving any kind of resources.

2. Based on the multidimensionality of the term «resource saving»:

- the process of permanent resolution of the contradiction between the resource saving effect of new equipment and technology and the regularity of development of production forces, the adaptive possibilities of the current economic mechanism;

- the presence of potential opportunities for improving the use of production resources;

- increasing the socio-ecological and economic efficiency of production while reducing its resource intensity;

- a decrease in the resource intensity of production or an increase in the final product with reducing in the volume of initial resources;

- scientific, production, organizational, commercial and information activities aimed at rational, complex use and economical consumption of all types of resources, based on the current level of development of technique and technology, while reducing technogenic impact on the environment;

- technical, economic and social policy to rationalize the generation, distribution and use of natural and other types of resources;

- production and sale of final products with a minimum consumption of substance and energy at all stages of the production cycle (from mining to marketing industries) and with the least impact on humans and natural systems; 
- one of the forms of realization of the reserves of the enterprise, associated with maximum savings in the production of material resources.

On the basis of the studied approaches, the definition of «resource management at the enterprise» is given as a target activity for planning and forecasting, organization, motivation, accounting, analysis, control, regulation of resource consumption at all stages of the life cycle of an enterprise, production processes. If we consider resource saving as an economic process, then the ecological component clearly prevails in its structure, since 32 $\%$ is accounted for by the ecological component. At the same time, $81 \%$ of waste can be used profitably through recycling and disposal of waste, most of which was obtained due to lack of thrift $[12,13]$.

In the development of existing theories, the priority of the environmental-oriented approach to resource saving management at the enterprise is substantiated, and its definition is given as a set of concepts, theories, scientific views and points of view, hypotheses on the sustainable development of socio-economic systems (when the production of goods and the satisfaction of needs of living generations does not cause damage, damage to nature and does not threaten a decrease in the level and quality of life of subsequent generations) and methodological tools that allow to describe, reveal the content of all processes of assimilation and human interaction with nature, qualitatively and quantitatively measure them, carry out the analysis and assess of the actual state and the expected consequences of this interaction from the standpoint of achieving environmental, social, economic effects.

The second important result was obtained on the basis of a comparative review of environmentally oriented scientific schools and concepts and substantiation of the scientific and practical significance of the ideas of the school of urban metabolism, which studies «urban flows of water, materials and nutrients» in the formation of the concept of «lean manufacturing» as a methodological basis for building an effective resource-saving management at the enterprise [14, 15].

It is proposed to use a classification that includes 5 groups of resources (material substantial, material financial, labor, information and energy), which made it possible to determine methodological approaches to resource saving management, to clarify and meaningfully disclose a set of resource saving management methods in the context of determining technological methods, organizational, economic methods which provide savings in resource consumption per unit of useful effect (work) for a new version of the introduced technology, resource-saving measures or solutions in comparison with the replaced option.

In order to achieve the set objectives, a study of external factors of resource saving was carried out, it showed that the metallurgical industry is one of the basic ones for the Russian economy, has the most important socio-economic importance, providing: $18.5 \%$ of the total volume of industrial production in the country and $16.6 \%$ - in the Volgograd region, including more than $10 \%$ non-ferrous metallurgy, from 6 to $8 \%$ - black metallurgy [1618]. In the regions where metallurgical plants are located, their share in the gross regional product and budgetary receipts ranges from $50 \%$ to $90 \%$, which fully applies to the Volgograd region. This industry accounts for $10 \%$ of jobs in the country; the metallurgical enterprises employ 1,300 thousand people; about 5 million more people employed in industries existing to provide the needs of metallurgy. However, it was found that resource saving in the industry is being implemented insufficiently, the negative impact on the environment is objectively observed, according to the results of environmental ratings, for example, Volgograd and other cities where large metallurgical enterprises operate, are in the lower positions. The relevance of resource saving in the metallurgical industry is determined by its strategically important positions for the national and regional economy [19-21]. 
The research of internal factors of resource saving at the enterprise showed that gross profit was received in the amount of $67.56 \%$ of the planned profit for the reporting period; it is due to the change in the timing of work and the excess of the actual costs of all resources over the planned ones.

This excess is due to JSC VMP «Krasny Oktyabr» performed additional works with low profitability, which were carried out mainly at the objects and were not envisaged by the plan. The transference of the work execution time affected the decrease of profitability of gross production. The actual indicator of profitability of gross production was $5.9 \%$, which is $2.8 \%$ lower than the planned one. According to the indicators of the effectiveness of the use of labor resources, it follows that their use is not entirely effective. We will focus on turnover and use of working hours of the entire sample of indicators. So, the turnover ratio for hiring is 0.20 at the end of the period, and the turnover ratio for dismissals is $0.15 \%$, since there are more hired employees than fired ones. We note that there are no dismissals of employees due to violation of labor discipline (absenteeism) at this enterprise, but the reasons for dismissals, except for retirement age, in the first place are awful working conditions, lack of growth prospects, and unsatisfactory compensation for harmful conditions. It is also confirmed by the data on losses of working time: the largest losses of working time in each analyzed year are losses due to illness. If they amounted to $39 \%$ of the total losses in 2018, then $37.5 \%$ - in 2019 and they decreased to $33.3 \%$ in 2020, but it is also a high indicator.

In the workshops of the enterprise, emissions of carbon monoxide are observed, sulfur dioxide is emitted - at sinter plants, in the blast furnace shop and in the mixing department of steel-making shops, although the concentration of sulfur dioxide in the air does not exceed the maximum permissible $\left(10 \mathrm{mg} / \mathrm{m}^{3}\right)$, gas emissions and dust are also observed, predominantly in shops and in the areas of charge preparation (contains up to $15-20 \%$ and more free and amorphous silicon dioxide, over $50 \%$ of iron oxides and other impurities); noise (from 90 and over $100 \mathrm{~dB}$ ) [22-24].

Resource saving is achieved on the basis of the labor organization not to wear out people, not to harm health and allow to earn decent money, which is possible on the basis of the introduction of the concepts of «lean manufacturing» [25-28]. Despite the carried out inspections, the enterprise was not technically and economically ready for a fundamental change in its production base and jobs, as it is shown by the experience of successful metallurgical enterprises JSC «Nizhny Tagil Metallurgical Plant», JSC «Volzhsky Pipe Plant», JSC «Vyksa Metallurgical Plant» - typical for the metallurgical industry, the more the last enterprise is the undoubted leader in the successful implementation of thrifty production with worldwide recognition [29]. The experience of these enterprises, and especially of the leading one, shows that it is important to teach people about lean manufacturing approaches constantly, daily and persistently.

\section{Results and discussion}

The basis for the formation of the ideology of «lean manufacturing» is standardization [3032]. The authors define the standard of resource saving at the enterprise, as a regulatory document of the organization, which defines a set of norms, requirements for the resource saving management system, rules of application and characteristics of production processes. A structural and logical model of the economic mechanism of resource saving and an algorithm for its implementation at the enterprise are developed (Fig.). 


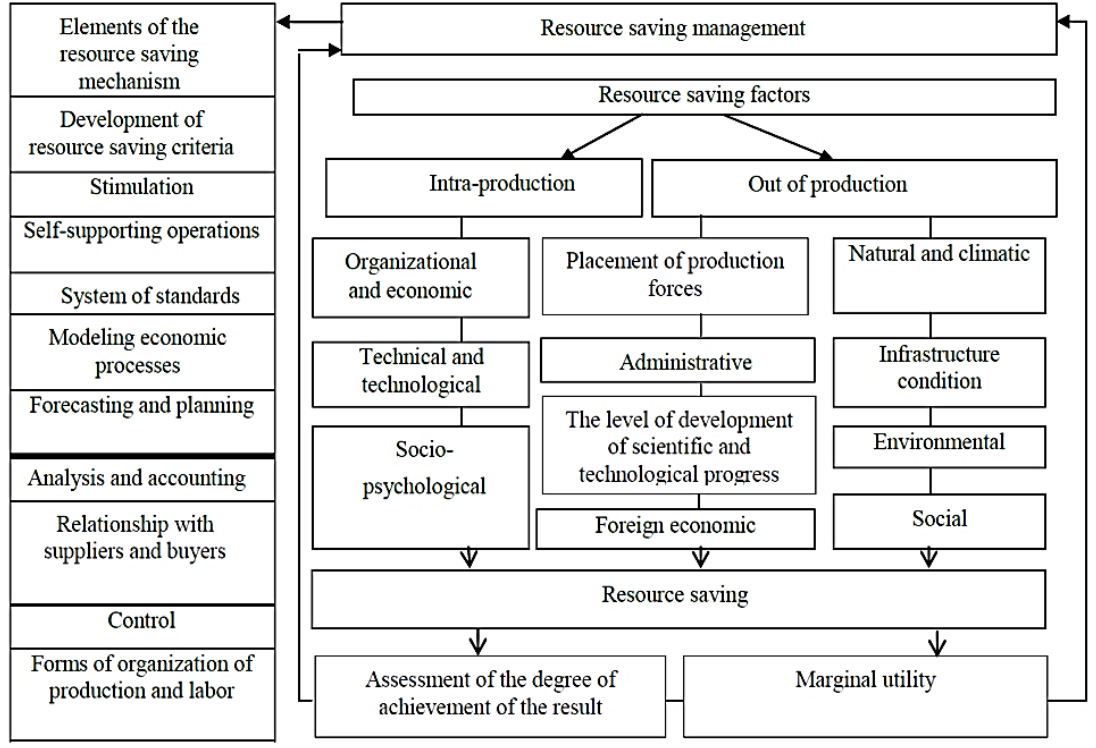

Fig. The economic mechanism of resource saving management at the enterprise.

As a tool for this mechanism, the authors have developed a program for the phased implementation of lean manufacturing in JSC VMP « Krasny Oktyabr», which includes two main sections:

Section 1 - General information. It gives the formulations and name of the project, the period of the project implementation, the basis for the project, the purpose and the organizational structure of the project;

Section 2 - Composition and content of the program stages. This section provides details of all decisions, stages, functions of all participants, measures and activities, as well as expected results, the decisions are presented in: organizing the implementation of the program; evaluation and selection of objects; formation and implementation of thrifty production implementation subprograms; training of labor resources of working groups; corporate rules for applying lean manufacturing; formation of a base of standard solutions; control of program execution; corporate requirements for the production system of JSC VMP «Krasny Oktyabr»; implementing the thrifty production program throughout the enterprise. The program is designed for three years - 2021-2024. As an element of the program, a resource saving plan was developed using the example of the pilot subdivision of JSC VMP « Krasny Oktyabr» for 2021, taking into account the use of automation tools, which will lead to a decrease in the time norm (that is, to the use of the progressive rate setting method) (Table 1). It is also necessary to increase the productivity of specialists who are engaged in finding clients, preparing projects, ensuring an adequate level of stocks of material resources, etc. But such an increase in the volume of work is impossible only due to a decrease in the time norm - it is important to increase in the productivity of specialists who are engaged in finding clients, preparing projects, ensuring an adequate level of stocks of material resources, etc.

Table 1. Changing the time norms when automating a separate technological process.

\begin{tabular}{|l|c|c|}
\hline \multicolumn{1}{|c|}{ Type of work } & Time norm before automation & Time norm after automation \\
\hline Grinding 1 & 27.8 & 12.5 \\
\hline Grinding 2 & 31 & 18 \\
\hline Grinding 3 & 20.3 & 15.3 \\
\hline
\end{tabular}


Automation of the production process will affect the productivity of the teams (Table 2).

Table 2. Productivity changes due to automation.

\begin{tabular}{|l|c|c|c|}
\hline Brigade & Before automation & After automation & Increase in productivity \\
\hline Grinder & 6.55 & 14.57 & 8.02 \\
\hline Grinder & 6.55 & 11.28 & 4.73 \\
\hline Grinder & 6.54 & 8.67 & 2.13 \\
\hline
\end{tabular}

Such an increase in labor productivity will affect the volume of work (Table 3).

Table 3. Change in production volumes after automation, $\mathrm{m}^{2}$.

\begin{tabular}{|l|c|c|c|}
\hline Type of work & Before automation & After automation & Increase in production volume \\
\hline Grinding 1 & 6730 & 14971 & 8187 \\
\hline Grinding 2 & 5970 & 10281 & 4311 \\
\hline Grinding 3 & 12698 & 16847 & 4149 \\
\hline Total & 25398 & 42099 & 16647 \\
\hline
\end{tabular}

Changes in production volumes will affect the amount of revenue (Table 4).

Table 4. Change in the volume of revenue after automation, thousand rubles.

\begin{tabular}{|l|c|c|c|}
\hline \multicolumn{1}{|c|}{ Type of work } & Before automation & After automation & Increase in revenue \\
\hline Grinding 1 & 3365 & 7485.50 & 4093.50 \\
\hline Grinding 2 & 3343.2 & 5757.36 & 2414.16 \\
\hline Grinding 3 & 54426.4 & 75487.52 & 18590.71 \\
\hline Total & 64134.6 & 88730.38 & 25098.37 \\
\hline
\end{tabular}

Therefore, it is proposed to create a fund for progressive bonuses to employees for saving resources. This fund is formed on the basis that $1 \%$ of the increase in gross profit accounted for $0.3 \%$ of the increase in wages. The progressive bonus fund will amount to 12004.489 thousand rubles. Carrying out the proposed measures within the framework of this standard for resource saving in the pilot unit will bring the following economic effect on these indicators (Table 5).

Table 5. Economic effect from the implementation of the plan and the resource-saving mechanism in the pilot unit.

\begin{tabular}{|l|c|c|c|}
\hline \multicolumn{1}{|c|}{ Indicator } & $\begin{array}{c}\text { Before measure } \\
\text { implementation }\end{array}$ & $\begin{array}{c}\text { After } \\
\text { implementation }\end{array}$ & Change \\
\hline \multicolumn{1}{|c|}{1} & 2 & 3 & 4 \\
\hline Time rate & 26.4 & 15.3 & 11.1 \\
\hline Brigade productivity & 6.55 & 11.5 & 4.95 \\
\hline Cost price, thousand rubles & 29519.427 & 46449.134 & 16929.707 \\
\hline Volume of realization, m ${ }^{2}$ & 25399 & 42099 & 16700 \\
\hline Sales volume, thousand rubles & 64134.6 & 88730.38 & 24595.78 \\
\hline Gross profit, thousand rubles & 34615.17 & 41921.246 & 7306.076 \\
\hline Net profit, thousand rubles & 27136.29 & 32768.89 & 5632.6 \\
\hline Return on sales, \% & 42.3 & 36.9 & -5.4 \\
\hline Profitability of production & 0.919 & 1.42 & 0.501 \\
\hline
\end{tabular}

Summarizing, we note that it was proposed to implement the program for a phased transition to «lean manufacturing», and it is carried out a technical and economic justification of certain measures for resource saving with the development and 
implementation of progressive norms on the example of a pilot unit, as a result of which a fund for progressive bonuses to employees for saving resources is expected.

This fund is planned to be created on the basis that $1 \%$ of the increase in gross profit accounts for $0.3 \%$ of the increase in wages. Gross margins (for a given process and division) are expected to increase by $21 \%$ salary fund by $6 \%$.

\section{Conclusions}

1. A brief analysis of the external factors of resource saving at the enterprise is performed: the state of the metallurgical industry was analyzed, it was revealed that the metallurgical industry is one of the basic ones for the Russian economy and has the most important socioeconomic importance in the framework of sustainable development of cities, providing: $18.5 \%$ of the total volume industrial production in the country; $18 \%$ of the total volume of Russian exports; about $10 \%$ of jobs in the country (1300 thousand people are employed; and about 5 million people are employed in industries that exist to meet needs). It was revealed that, resource saving is implemented in metallurgy at the insufficient pace, since a negative impact on the environment is objectively observed, according to the results of environmental ratings, for example, Volgograd and other cities, where large metallurgical enterprises operate, are in the lower positions. The priority of resource saving is determined by its strategically important positions for the sustainable development of cities in the metallurgical industry.

2.The internal factors of resource saving are analyzed at the enterprise and the assessment of the efficiency of using resources is given: labor, material-production, financial. The use of labor resources is not quite effective: the hiring turnover ratio is 0.20 at the end of the period, and the dismissal turnover ratio is $0.15 \%$, since there are more hired employees than fired ones. The main reason for dismissal is awful working conditions, lack of growth prospects, unsatisfactory compensation for harmful conditions, which is confirmed by significant losses of working time due to illness (39\%, 37.5\% and $33.3 \%$ in 2018-2020, respectively). It reflects the negative dynamics of financial indicators: at the beginning of 2021, revenue amounted to 7.3 billion rubles ( 2.5 times less than in 2018); uneven and negative profit dynamics (at the beginning of $2021-1.5$ billion rubles); uneven and negative dynamics of the enterprise value (at the beginning of 2021 534 million rubles, that is 2 times less than the level of 2018).

It was revealed that significant environmental problems are observed in the workshops of the enterprise, they negatively affect labor productivity and, in general, the efficiency of production and economic activities. The eco-oriented approach and the transition to « lean manufacturing « is a proven way of overcoming the crisis, increasing the financial and economic efficiency, and the competitiveness of an enterprise in the context of sustainable urban development.

3. The definition of the standard of resource saving at the enterprise is given and it is substantiated that the main direction of standardization in the field of resource saving is the establishment of provisions, which regulate the level and conditions of resource consumption for the production of works and products of enterprises, in the standards.

4. The main elements of resource saving management at the enterprise have been developed: the structural-logical model of the economic mechanism of resource saving management and the algorithm for implementing this model at the enterprise. Measures have been developed for progressive rationing and progressive bonuses to employees for saving resources. A production-thematic plan has been developed for resource saving according to which the measures have been developed to standardize the technological 
process, taking into account the use of automation tools, which will lead to a decrease in the time norm.

Thus, all the tasks have been solved, the goal has been achieved, and the working hypothesis has been confirmed.

\section{References}

1. L. Qiao, M. Li, Y. Zhang, X. Zhao, Research on the construction of the urban wetland park environment based on resource saving and environment friendliness, Nature Environment and Pollution Technology, 15, 221-226 (2016)

2. E. Lopatin, Methodological approaches to research resource saving industrial enterprises, International Journal of Energy Economics and Policy, 9, 181-187 (2019)

3. G. Liobikiene, A. Minelgaite, Energy and resource-saving behaviours in European Union countries: The Campbell paradigm and goal framing theory approaches, Science of the Total Environment, 750 (2021)

4. A. Lubnina, M. Shinkevich, S. Ashmarina, N. Zaitseva, G. Sayfutdinova, I. Ishmuradova, Resource saving innovative forms of the industrial enterprises, International Journal of Economics and Financial Issues, 6(2), 479-483 (2016)

5. A. Ongdash, Z. Zhorabayeva, B. Uteyev, M. Gubaidullina, E. Ongdashuly, Resourcesaving problems: World experience and Kazakhstan, Academy of Accounting and Financial Studies Journal, 22 (2018)

6. O. Maksimchuk, T. Pershina, Innovative means of energy efficiency management for regional industrial enterprises, SHS Web of Conferences, 35, 01008 (2017)

7. N. Gareeva, A. Starodubova, A. Romanova, The region's competitiveness assessment on the basis of «sustainable development» concept, IOP Conference Series: Materials Science and Engineering, 890 (1) (2020)

8. G. Putnik, P. Avila, Governance and Sustainability (Special Issue Editorial), Int. J. Ind. Syst. Eng., 24,137-143 (2016)

9. E. Tshovrebov, Resource-saving: main formation stages, theories and methods, tendencies and prospects of development in industry and construction of Russia, Vestnik MGSU, 1, 112-158 (2020) DOI: 10.22227/1997-0935.2020.1.112-158

10. P. Danilovich, Energy saving, alternative sources of energy. International Journal of Mechanical Engineering and Technology, 9(3) 405-412 (2018)

11. S. Kiyko, E. Druzhinin, O. Prokhorov, B. Haidabrus, Logistics control of the resources flow in energysaving projects: Case study for metallurgical industry, Acta Logistica, 7, 49-60 (2020)

12. T. Saurin, G. Tortorella, M. Soliman, J. A. Garza-Reyes, Lean production myths: an exploratory study. Journal of Manufacturing Technology Management, 32, 1-19 (2020) DOI: $10.1108 / J M T M-08-2020-0302$

13. I. A. Mouzani, D. Bouami, The integration of lean manufacturing and lean maintenance to improve production efficiency, International Journal of Mechanical and Production Engineering Research and Development, 9, 593-604 (2019) DOI: 10.24247/ijmperdfeb201957

14. L. E. Abbadi, S. Elrhanimi, S. E. Manti, A literature review on the evolution of lean manufacturing. Journal of System and Management Sciences, 10, 13-30 (2020) DOI: 10.33168/JSMS.2020.0402

15. J. Trout, Lean Manufacturing Explained, Reliable Plant, (Noria C., 2020) URL: https://www.reliableplant.com/Read/30267/lean-manufacturing-techniques (last accessed 20.02.2021) 
16. S. Kiyko, E. Druzhinin, O. Prokhorov, B. Haidabrus, Multi-agent Model of Energy Consumption at the Metallurgical Enterprise. In Lecture Notes in Mechanical Engineering , 156-165 (2020) DOI: 10.1007/978-3-030-50794-7_16

17. N. Kazakova, V. Kogdenko, Monitoring of the main parameters of environmental safety of industrial production, Ecology and Industry of Russia, 25(3), 60-65 (2021) DOI: 10.18412/1816-0395-2021-3-60-65

18. O. Ustimkin, Development of ferrous metallurgy in Russia. Innovative prospects of the industry, Economics and management of innovative technologies, 1(76), 11 (2018)

19. R. C. Gupta, Energy Resources, Its Role and Use in Metallurgical Industries, Treatise on Process Metallurg,. Elsevier Ltd. 3, 1425-1458 (2014) DOI: 10.1016/B978-0-08096988-6.00034-1

20. E. Karpenko Conceptual foundations of the formation of a resource-saving management mechanism in the metallurgical industry of Russia, Economic Bulletin of the Donbass State Technical Institute, 6, 29-35 (2020)

21. Y. Amosova, Eco-friendly production as an element of sustainable development of metallurgical enterprises, Bulletin of the South Ural State University. Series: Metallurgy, 19(1), 43-49 (2019)

22. Joint stock company «Volgograd metallurgical plant» Krasny Octyabr», URL: https://www.vmzko.ru/ (last accessed: 02.02.2021)

23. M. Mironova , A. Romanova, E. Ilina, I. Galeeva, D. Egorov, A. Akhmetova, Environmental activities of a petrochemical company as a sustainable factor of the city and region, IOP Conference Series: Materials Science and Engineering, 890(1), 012199. (2020) DOI:10.1088/1757-899X/890/1/012199

24. R. Safiullin , J. Kareeva, Formation and motion of droplets in gas cleaning devices with porous rotating atomizers, IOP Conference Series: Materials Science and Engineering, 890 (1), 012159 (2020) DOI:10.1088/1757-899X/890/1/012159

25. P. Martinez-Jurado, J. Moyano-Fuentes, Lean management, supply chain management and sustainability: A literature review, J. Clean. Prod., 85, 134-150 (2014)

26. L. Varela, A. Araujo, P. Avila, H. Castro, G. Putnik, Evaluation of the relation between lean manufacturing, industry 4.0, and sustainability, Sustainability (Switzerland), 11 (2019) DOI: 10.3390/su11051439

27. N. Garcia-Buendia, J. Moyano-Fuentes, J. M. Maqueira Marín, Lean supply chain management and performance relationships: what has been done and what is left to do, CIRP Journal of Manufacturing Science and Technology, 32, 405-423 (2021) DOI: 10.1016/j.cirpj.2021.01.016

28. R. Henao, W. Sarache, I. Gomez, Lean manufacturing and sustainable performance: Trends and future challenges, Journal of Cleaner Production, 208, 99-116 (2019)

29. M. Grishina, Testing the methods of reconstruction of the spatial solution of the pedestrian street, IOP Conf. Series: Materials Science and Engineering, 890(1), 012026 (2020) DOI:10.1088/1757-899X/890/1/012026

30. A. Frank, L. Dalenogare, N. Ayala, Industry 4.0 technologies: Implementation patterns in manufacturing companies, International Journal of Production Economics, 210, 1526 (2019)

31. O. Maksimchuk, T. Pershina, A new paradigm of industrial system optimization based on the conception industry 4.0., MATEC Web of Conferences, 129, 04006 (2017)

32. C. Sancha, F. Wiengarten, A. Longoni, M. Pagell, The moderating role of temporary work on the performance of lean manufacturing system, International Journal of Production Research, 58, 4285-4305 (2020) 